\title{
Metamodels for Optimum Design of Outer-Rotor Synchronous Reluctance Motor
}

\author{
Ludmila Lavrinovicha (Doctoral Student, Riga Technical University), \\ Roman Dobriyan (Master Student, Riga Technical University), \\ Oskars Onzevs (Leading Researcher, School of Business Administration "Turiba”)
}

\begin{abstract}
A new design of synchronous reluctance motor with segment-shaped outer rotor is presented and investigated in this paper. In order to obtain correct recommendations for optimal design of the studied synchronous reluctance motor, analytical relations of motor electromagnetic parameters and geometrical dimensions (also known as metamodels) have been synthesized. Electromagnetic parameters, which have been used for metamodels synthesis, are obtained by means of magnetostatic field numerical calculations with finite element method using software QuickField.

The paper includes the analysis of the studied synchronous reluctance motor geometrical parameters (stator outer diameter, height and overlap angle of rotor's segment-shaped packages) influence on the electromagnetic torque per unit volume. Testing of synthesized metamodels shows that relative difference between the results obtained by numerical calculations and those obtained with the help of synthesized metamodels does not exceed eight percent at experimental points and intermediate points as well.

The proposed optimal design of the segment-shaped outerrotor synchronous reluctance motor obtained with the help of synthesized metamodels has been compared with a salient-pole outer-rotor synchronous reluctance motor having ferromagnetic yoke with the same value of the electromagnetic torque.

The comparison results of both motors show that the highest value of electromagnetic torque per unit volume can be achieved with the proposed new design of the synchronous reluctance motor with segment-shaped outer rotor.
\end{abstract}

Keywords - AC motors; Design optimization; Magnetostatics; Metamodeling; Finite element analysis.

\section{INTRODUCTION}

The development of new materials and new manufacturing technologies has accelerated over the last several years. It is leading to the increase of requirements to electric motors being basic elements in the electric drives and mechanical systems.

The high reliability, durability in difficult operating conditions, low energy consumption and low production cost are the main requirements to the electric motors.

In this connection brushless synchronous electric motors, especially synchronous reluctance motors (SynRM) with electronic commutation are attracting more and more attention with application in low power electric tools.

In SynRM permanent magnets and a special excitation winding does not exist. Thus, they are more reliable and their production is cheaper than other types of electric motor. The SynRM is an electric motor in which electromagnetic torque is produced by the magnetic asymmetry along direct axis (daxis) and quadrature axis (q-axis) of the motor $[1,2]$.

However, mostly applied SynRM constructions do not provide high value of electromagnetic torque per unit volume. If it were possible to get rid of this disadvantage, the SynRM would be the most reliable for the use in the modern low power electric tools.

In this connection, it is important to find a new optimal design of SynRM that can provide relatively high value of electromagnetic torque per unit volume of the motor and, at the same time, low cost and simple technology of its production.

The SynRM is a type of brushless motors that can be designed in different variations. Depending on the requirements to the motors application, it can be built with an inner rotor and an outer rotor as well [3].

The outer-rotor design of electric motors makes it possible to use them for direct integration into an operating element of the high-torque electric device without transmission gears. It can significantly increase service life and energy performance of a device in general.

Outer-rotor motors can be applied, for instance, as an electric drive in electric vehicles, in the drives of ventilators, and other electric tools $[4,5]$.

The aim of this research is to synthesize the metamodels for analyzing and optimization of the new design of SynRM with segment-shaped outer rotor.

\section{DESIGNS OF THE OUTER-ROTOR SYNRM}

A salient-pole rotor is the simplest rotor construction applied for the outer-rotor SynRM. Typical two-pole SynRM with salient-pole outer rotor is presented in Fig.1. It has inner stator 1 with three phase windings in its slots, outer rotor with two salient poles 2, and ferromagnetic yoke 3 as well.

However salient-pole SynRM has one significant disadvantage: relatively low torque per unit volume.

Thus, it has been decided to design new SynRM (Fig.2.). New design of the SynRM has inner stator 1 with three phase windings in its slots and outer rotor, which is designed as two segment-shaped ferromagnetic packages 2. Segment-shaped ferromagnetic packages are magnetically isolated from each other with non-magnetic spaces [6].

It is important to mention that the main magnetic flux $\Phi_{d}$ is directed along d-axis of the motors as it is shown in Fig. 1 and Fig 2. 


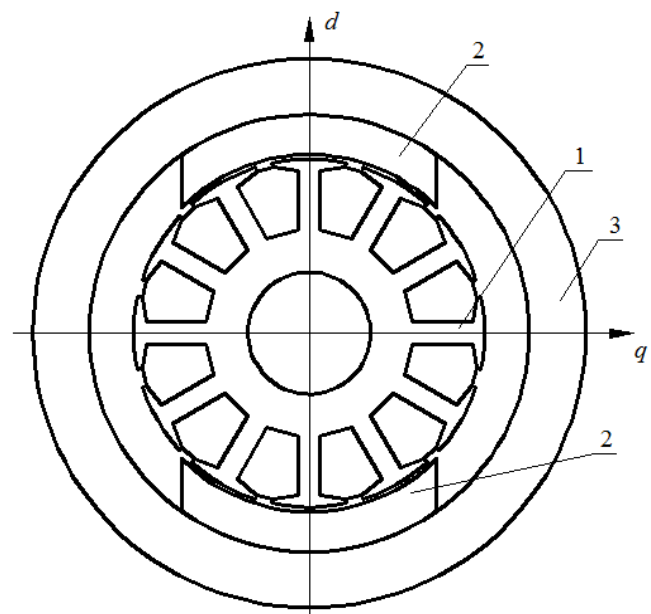

Fig. 1. Construction scheme of SynRM with salient-pole outer rotor and ferromagnetic yoke.

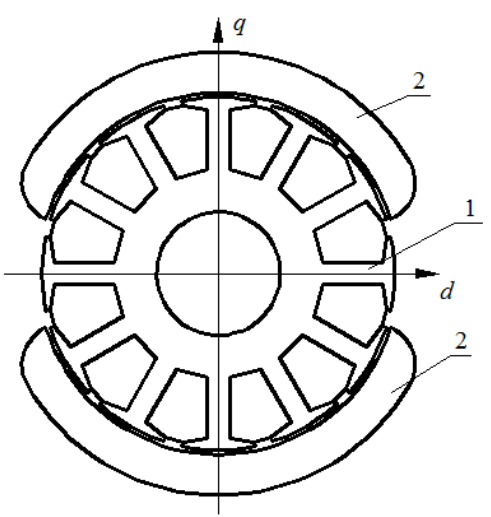

Fig. 2. Construction scheme of new design SynRM with segment-shaped outer rotor.

\section{Parameters of New Design SynRM with SEgment- SHAPED OUTER ROTOR}

In order to obtain recommendations concerning the optimal design of the new SynRM with segment - shaped outer rotor for the maximum value of electromagnetic torque per unit volume it is necessary to analyze how the motor electromagnetic parameters depend on motor dimensions and segment-shaped packages form variations.

Thus, three independent factors that mostly influence the value of electromagnetic torque per unit volume are considered:

- outer diameter of the stator $D_{s}$;

- height of rotor's segments shaped packages $h_{s}$;

- overlap angle of segments shaped packages $\alpha_{s}$.

The main dimensions of the motor are shown in Fig.3.

Varying boundaries for selected impact factors are presented in Table I.

For the analysis of the electromagnetic torque dependence on selected impact factors the motor shaft diameter and value of air-gap are assumed to be fixed according to the mechanical and constructive properties of the low power motor (up to 1 $\mathrm{kW}$ ) with high rotating speed (over $10000 \mathrm{rpm}$ ).

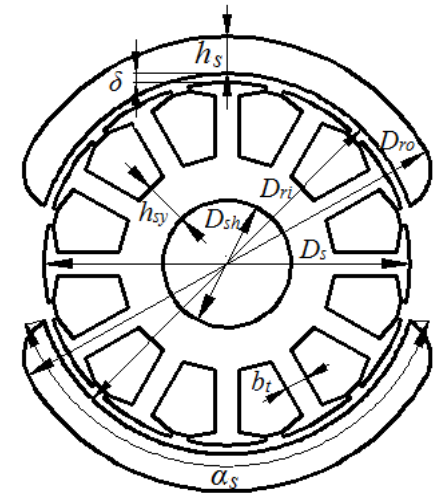

Fig. 3. Geometry of new design SynRM with segment-shaped outer rotor.

TABLE I

IMPACT FACTORS FOR NUMERICAL EXPERIMENTS

\begin{tabular}{|l|l|l|l|}
\hline \multirow{2}{*}{ Impact Factors } & \multirow{2}{*}{ Labels } & \multicolumn{2}{|l|}{ Boundary } \\
\cline { 3 - 4 } & & Min & Max \\
\hline Rotor's segment overlap angle, $(\mathrm{deg})$ & $\alpha_{s}$ & 117 & 171 \\
\hline Rotor's segment height, $(\mathrm{mm})$ & $h_{s}$ & 4.5 & 8.4 \\
\hline Outer diameter of the stator, $(\mathrm{mm})$ & $D_{s}$ & 40 & 46 \\
\hline
\end{tabular}

The shaft diameter is assumed as $D_{s h}=14(\mathrm{~mm})$, and the value of the air gap as $\delta=0.5(\mathrm{~mm})$. The maximum value of total current in the stator slot is $I_{m}=200 \mathrm{~A}$.

The values of stator tooth width $b_{t}$ and stator yoke height $h_{s y}$ depend on the stator outer diameter at constant surface of the stator slot. Inner diameter of the rotor $D_{r i}$ also depends on the outer stator diameter at constant value of the air-gap.

Seven evenly arranged values have been selected for each factor from the given examined range.

In order to evaluate the influence of all impact factor combinations in the investigated motor, the following number of numerical experiments is necessary to implement:

$$
k=p^{n}=7^{3}=343
$$

where $k$ is the number of numerical experiments;

$p$ is the number of values selected from the range of the impact factor;

$n$ is the number of impact factor.

In practice, it is quite complicated to examine all combinations of the impact factors due to large number of experiments.

Therefore, according to the method of the rational design of the experiments [7,8] 49 combinations of impact factors have been selected, such as they evenly cover all the examined range.

\section{Numerical CAlculation of the Electromagnetic TORQUE}

The analysis of the influence of selected impact factors on the value of electromagnetic torque per unit volume can be realized with numerical calculation by finite element method using different software that are provided for magnetic field simulations. 
QuickField is widely applied software for the twodimensional magnetic field simulation by finite element method with consideration of magnetic saturation [9].

Results, reported in paper [10], show that software QuickField can provide the correct results of the electric motor magnetic field simulation and electromagnetic parameters calculations.

Electromagnetic torque of the motor with software QuickField is calculated with Maxfell's stress method.

According to the Maxfell's stress method the electromagnetic torque is calculated with integral (1) along a line in the middle of the air gap of the motor; then multiplying the result by the active length of the motor $[9,11]$.

For the construction of the electromagnetic torque-angle curve, the torque is necessary to calculate at different values of the angle between magnetomotive force (MMF) vector and daxis of the motor.

$$
T=\frac{1}{2} \oint_{s}([r \times H](n \cdot B)+[r \times B](n \cdot H)) d s,
$$

where $r$ is the radius vector of the point of integration; $n$ is the vector of the outward unit normal; $B$ is the vector of the magnetic flux density; $H$ is the vector of magnetic field intensity and is equal to $H=\mu^{-1} \mathrm{~B}$, where $\mu$ is the magnetic permeability tensor.

\section{V.METHOD FOR METAMODEL SYNTHESIS}

The method based on the regression model has been used in this paper for the metamodel synthesis on the basis of results of numerical calculations of the studied motor electromagnetic torque.

The method that is presented in the paper [12] is widely used for the metamodel synthesis. This method is simultaneously meeting two mutually exclusive requirements - the accuracy and the efficiency. It has been successfully applied for solution of the electric machine optimization problems in different papers, for instance [13, 14].

According to the method that is described in paper [12] the metamodel is synthesized as a sum of elementary functions from the functions' bank, and the obtained relation has the following description:

$$
Y=A_{0}+\sum_{i=1}^{m-1} A_{i} g_{i}(X),
$$

where $X$ is the value of the variable factor; $g_{i}(X)$ is the $i$-th elementary function selected from the bank; $A$ is the coefficient obtained by means of the method of the least squares;

$m$ is the number of the elementary functions selected from the bank.

The elementary functions in the bank have the following description:

$$
g_{i}(X)=\prod_{j=1}^{n} X_{j}^{a_{i j}}
$$

where $a_{i j}$ is the index of each the $j$-th variable factor in the $i$-th function (can be a positive or negative number).

The synthesis of metamodel has two stages.

In the first stage, the sufficient number of perspective elementary functions is selected and the preliminary sum of them as a metamodel (3) is obtained.

Each elementary function is selected for the minimum difference $\Delta$ :

$$
\Delta=A_{0}=\sum_{i=1}^{m-1} A_{i} g_{i}(X)-Y .
$$

The preliminary obtained metamodel is more complicated than necessary. Thus, the second stage is the optimization of the metamodel complexity.

The optimization of the obtained metamodel complexity is made by cutting down the elementary functions that have less influence on the inside criteria $\sigma$ :

$$
\sigma=\frac{1}{\sqrt{k-m+1}} \sqrt{\sum_{i=1}^{k}\left(A_{0}+\sum_{i=1}^{m-1} A_{i} g_{i}(X)-Y\right)^{2}},
$$

The accuracy of the synthesized metamodel is defined by a correlation coefficient, which is the relative average squared deviation:

$$
C=\left(1-\frac{\sigma}{\sigma_{0}}\right) \cdot 100 \%
$$

where

$$
\sigma_{0}=\sqrt{\frac{\sum_{i=1}^{k}\left(Y_{i}-\frac{1}{k} \sum_{i=1}^{k} Y_{i}\right)^{2}}{k-1}} .
$$

To define the metamodel with the optimal relationship between accuracy and complexity, the elimination diagram is constructed. The example of elimination diagram is presented in Fig. 4.

The breaking point on elimination diagram (Fig.4.) determines the metamodel with optimal complexity and accuracy.

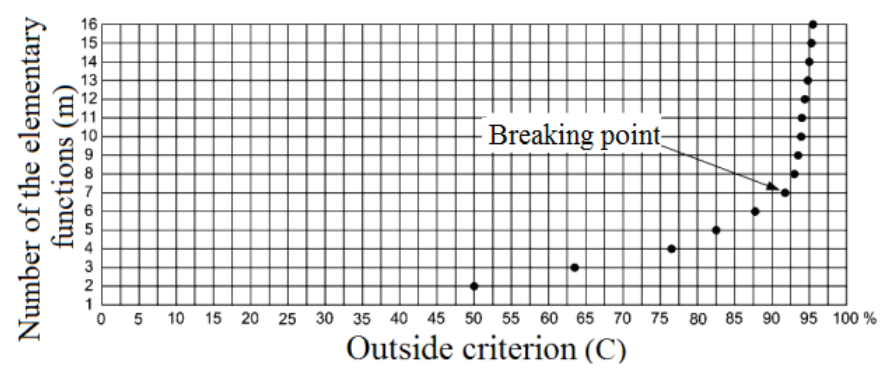

Fig. 4. Elimination curve of outside criterion.

\section{Metamodels for New Design SynRM}

According to the mentioned above method of numerical calculations of electromagnetic torque and method of metamodel synthesis, the following analytical relation 
between maximum value of electromagnetic torque per unit volume and selected variable factors is synthesized:

$$
\begin{aligned}
& T / V=-2.964-1.366 \frac{1}{\alpha_{s}^{*}}+3.557 \frac{1}{h_{s}^{*}}+4.25 h_{s}^{*}- \\
& -1.205 \alpha_{s}^{*}-0.155 \frac{D_{s}^{*}}{h_{s}^{*}}, \quad\left(\mathrm{Nm} / \mathrm{m}^{3}\right) \cdot 10^{3},
\end{aligned}
$$

where $\alpha_{s}^{*}=-1.667+0.01852 \cdot \alpha, \quad h_{s}^{*}=0.4196+0.01787 \cdot h$, $D_{s}^{*}=-6.167+0.167 \cdot D_{s}$.

When the SynRM operates as a motor with electronic commutation, depending on the applied control scheme of switches, it is possible to set different operating modes. One of them is when at changing the motor load and rotating frequency the angle $\varepsilon$ between the vector of MMF and d- axis of the rotor remains constant $[15,16]$.

Therefore, it is also necessary to find the optimal operating angle $\varepsilon$ that provides maximum value of the torque.

The angle between a vector of magnetomotive force and daxis of the motor for the maximum value of electromagnetic torque can be calculated with the following synthesized metamodel:

$$
\varepsilon=24.5+27.4 \alpha_{s}^{*}+D_{s o}^{*}, \quad(\mathrm{deg})
$$

In order to consider the magnetic saturation for the motor design optimization, the metamodels for maximum values of magnetic flux density in the rotor segment-shaped packages $B_{r}$, stator yoke $B_{s y}$ and stator teeth $B_{s t}$ have been synthesized in the similar way:

$$
\begin{aligned}
& B_{s y}=4.28-1.72 \cdot \frac{1}{\alpha_{s}{ }^{*}}+0.15 \cdot \frac{1}{\alpha_{s}{ }^{* 3}}-0.69 \cdot \frac{\alpha_{s}{ }^{*} \cdot D_{s}{ }^{*}}{h_{s}{ }^{*}}+ \\
& +0.38 \cdot \alpha_{s}^{* 2} \cdot D_{s}^{*}-0.63 \cdot \alpha_{s}^{* 2} \cdot h_{s}^{* 2}-0.06 \cdot \frac{\alpha_{s}^{*}}{D_{s}^{*} \cdot h_{s}^{* 2}}+ \\
& +0.09 \cdot \alpha_{s}^{*} \cdot D_{s}^{* 3},(T) \\
& B_{s t}=2.98-0.37 \cdot D_{s}{ }^{*}-1.89 \cdot \frac{1}{\alpha_{s}{ }^{*}}+1.45 \cdot h_{s}{ }^{*}- \\
& -1.44 \cdot \frac{h_{s}{ }^{*}}{D_{s}{ }^{*}}+0.41 \cdot \frac{1}{D_{s}{ }^{*} \cdot h_{s}{ }^{*}}+0.9 \cdot \frac{1}{\alpha_{s}{ }^{*} \cdot h_{s}{ }^{*}}- \\
& -0.25 \cdot \frac{1}{h_{s}^{* 3}},(T), \\
& B_{r}=-5.66+0.29 \cdot \frac{1}{\alpha_{s}{ }^{*}}+2.69 \cdot \frac{1}{h_{s}{ }^{*}}+3.37 \cdot h_{s}{ }^{*}+ \\
& +0.18 \cdot D_{s}^{*} \cdot \alpha_{s}{ }^{*}-0.1 \cdot \frac{1}{\alpha_{s}{ }^{2}}-0.007 \cdot \frac{1}{D_{s}^{* 2} \cdot \alpha_{s}{ }^{3}},(T) \text {. }
\end{aligned}
$$

The testing of synthesized metamodels shows that the relative difference of the results obtained with metamodels and by means of the finite element method does not exceed eight percent at calculated points as well as at intermediate points.

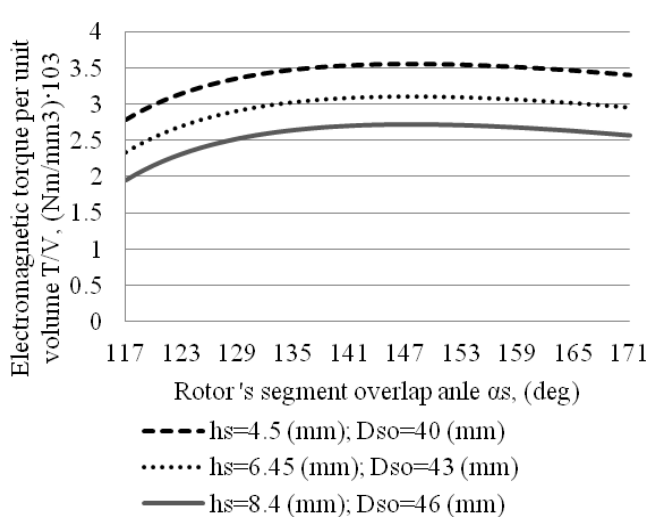

Fig. 5. Maximum value of electromagnetic torque per unit volume according to overlap angle of rotor's segment.

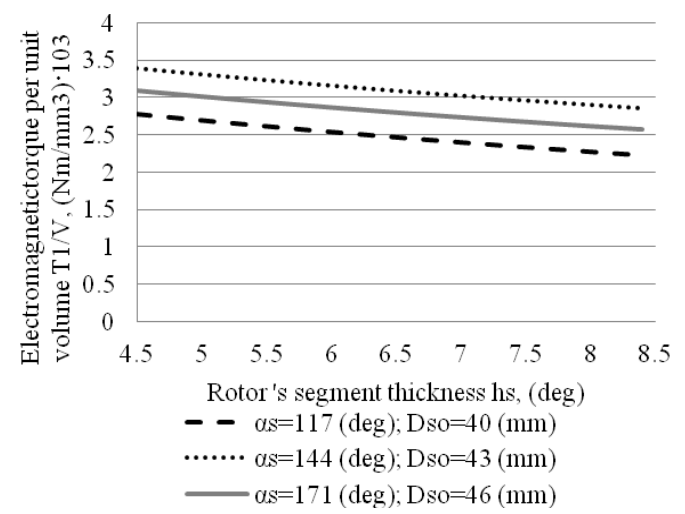

Fig. 6. Maximum value of electromagnetic torque per unit volume according to thickness of rotor's segment.

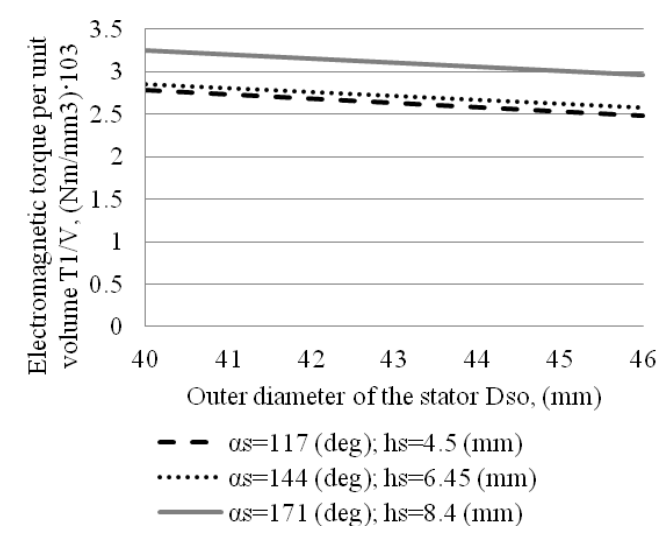

Fig. 7. Maximum value of electromagnetic torque per unit volume according to outer diameter of the stator.

As an example, Fig. 5 shows how the electromagnetic torque per unit volume of the new design SynRM is changing at variable overlap angle of rotor's segments at three different combinations of other impact factors.

Fig. 6 and Fig. 7 show the dependence of the electromagnetic torque per unit volume on rotor's segment thickness and outer diameter of the stator respectively.

\section{Metamodel Based Optimization OF THE OUTER- ROTOR SYNCHRONOUS RELUCTANCE MOTOR}

Optimization task in this paper is to obtain the optimal combination of the selected impact factors for the segment- 
shaped outer-rotor SynRM for providing of the maximum value of electromagnetic torque per unit volume at a given value of the total current $\left(I_{m}=200 \mathrm{~A}\right)$ in the stator slot and active length of the motor $(l=0.1 \mathrm{~m})$.

The values of magnetic flux density $2 T$ in stator teeth, 1.65 $T$ in rotor and the same $1.65 T$ in stator yoke are considered as restrictions for maximum values of flux density in magnetic circuit of the motor.

In order to maximize optimization function (10) the Microsoft Excel Solver [17] has been applied.

The picture of magnetic field and torque-angle characteristic for the optimized SynRM obtained with the help of software QuickField are presented in Fig. 8 and Fig. 9 respectively.

Values of magnetic flux density in the magnetic circuit of the optimized motor do not exceed preliminary assumed restrictions.

In order to evaluate obtained optimal design of the motor with outer rotor having segment-shaped packages, it is compared with the simplest, often used design one of the outer-rotor SynRM that has salient poles on the rotor and typical ferromagnetic yoke (Fig. 1.).

Geometry of compared SynRM with two salient poles is shown in Fig. 10. Value of the air gap, shaft diameter, motor active length, surface of the stator slots and value of the total current in the stator slots for the motor with salient poles are the same as for optimized SynRM with segment-shaped packages on the rotor.

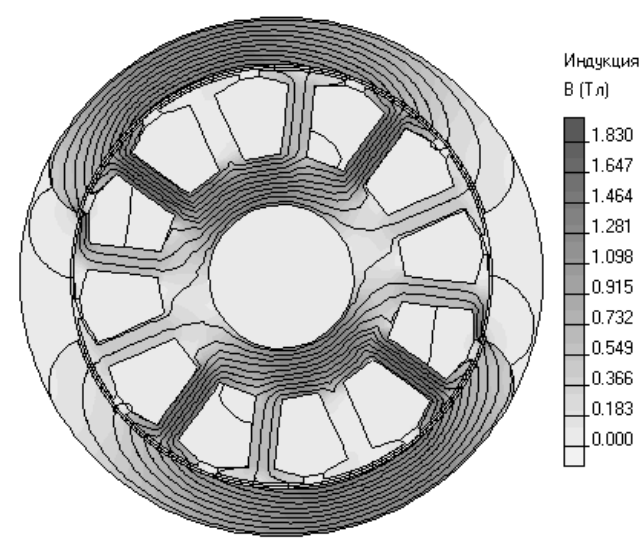

Fig. 9. Picture of magnetic field of the new design SynRM with segmentshaped outer rotor at $\varepsilon=54 \mathrm{deg}$.

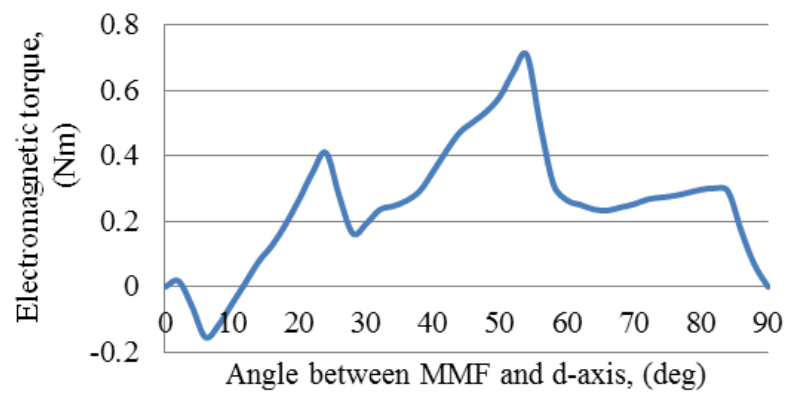

Fig. 10. Electromagnetic torque of the new design SynRM with segmentshaped outer rotor according to the angle between MMF vector and d-axis of the motor.
TABLE II

COMPARISON DATA

\begin{tabular}{|c|c|c|c|}
\hline Value & Labels & $\begin{array}{c}\text { SynRM with } \\
\text { segment-shaped } \\
\text { outer rotor }\end{array}$ & $\begin{array}{l}\text { SynRM with } \\
\text { salient-pole } \\
\text { outer rotor }\end{array}$ \\
\hline $\begin{array}{l}\text { Maximum value of the } \\
\text { torque, }(\mathrm{Nm})\end{array}$ & $\mathrm{T}$ & 0.7 & 0.7 \\
\hline $\begin{array}{l}\text { Angle between a } \\
\text { vector of } \\
\text { magnetomotive force } \\
\text { and d-axis, (deg) }\end{array}$ & $\varepsilon$ & 54 & 56 \\
\hline $\begin{array}{l}\text { Stator outer diameter, } \\
{[\mathrm{m}]}\end{array}$ & $D_{s}$ & 0.040 & 0.045 \\
\hline Stator yoke height, [m] & $h_{s y}$ & 0.0047 & 0.0072 \\
\hline Stator tooth width, $[\mathrm{m}]$ & $b_{t}$ & 0.0025 & 0.0038 \\
\hline $\begin{array}{l}\text { Package overlap angle, } \\
\text { [deg] }\end{array}$ & $\alpha_{s}$ & 145 & - \\
\hline $\begin{array}{l}\text { Pole overlap angle, } \\
\text { [deg] }\end{array}$ & $\alpha_{s}$ & - & 90 \\
\hline $\begin{array}{l}\text { Thickness of a } \\
\text { package, }[\mathrm{m}]\end{array}$ & $h_{s}$ & 0.0046 & - \\
\hline $\begin{array}{l}\text { Thickness of a pole, } \\
{[\mathrm{m}]}\end{array}$ & $h_{p}$ & - & 0.008 \\
\hline $\begin{array}{l}\text { Rotor inner diameter, } \\
{[\mathrm{m}]}\end{array}$ & $D_{r i}$ & 0.041 & 0.046 \\
\hline $\begin{array}{l}\text { Rotor outer diameter, } \\
{[\mathrm{m}]}\end{array}$ & $D_{r o}$ & 0.050 & 0.084 \\
\hline Rotor yoke height, [m] & $h_{r y}$ & - & 0.011 \\
\hline Motor volume, $\left(\mathrm{m}^{3}\right)$ & $V$ & 0.000196 & 0.000554 \\
\hline $\begin{array}{l}\text { Maximum value of } \\
\text { the electromagnetic } \\
\text { torque per unit } \\
\text { volume }\left(\mathrm{Nm} / \mathrm{m}^{3}\right) \cdot 10^{3}\end{array}$ & $T / V$ & 3.571 & 1.264 \\
\hline
\end{tabular}

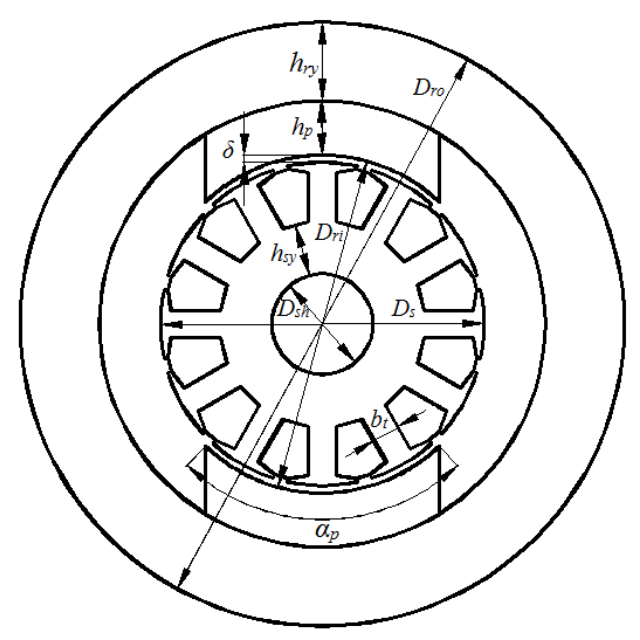

Fig. 11.Geometry of the salient pole SynRM with outer rotor. 
Other geometrical parameters have been found for the same value of maximum electromagnetic torque of the optimized SynRM considering preliminary assumed restrictions for magnetic flux values in the magnetic main elements of motor magnetic circuit. Comparison data between two motors are presented in Tab. II.

Analysis of presented results of comparison analysis (Table II) shows that the new segment-shaped design of outer rotor for SynRM can significantly minimize motor dimensions in comparison with the salient-pole rotor with ferromagnetic yoke at the same value of electromagnetic torque. At the same time, first motor can provide almost three time higher value of electromagnetic torque per unit volume than salient-pole SynRM.

\section{VIII.CONCLUSIONS}

Based on the results obtained in this research, the following conclusions can be drawn:

1. Results obtained by means of numerical calculations can be useful for synthesis of the metamodels, which characterize dependence of maximum value of electromagnetic torque per unit volume and other motor parameters on the impact factors.

2. The accuracy of the synthesized metamodels is acceptable for analysis and optimization of new design SynRM with segment-shaped outer rotor.

3. Optimal design of new SynRM with segment-shaped outer rotor allows achievement of the following advantages of the motor: relatively high value of the electromagnetic torque per unit volume, simple motor production, low cost and high durability in difficult operating conditions.

4. Comparison analysis between the studied motors shows that SynRM segment-shaped outer rotor has almost three times higher value of electromagnetic torque per unit volume than the motor with salient-pole rotor at the same value of the maximum electromagnetic torque and value of the total current in the stator slots.

\section{ACKNOWLEDGMENT}

This work has been supported by the European Social Fund within the project "Support for the implementation of doctoral studies at Riga Technical University" No. 2009/0144/1DP/1.1.2.1.2/09/IPIA/VIAA/005

\section{REFERENCES}

[1] I. Boldea, Reluctance Synchronous Machines and Drives, USA: Oxford University Press, 1996.

[2] T. J. E. Miller, Switched Reluctance Motors and their Control, Magna Physics Publishing and Oxford University Press, London, 1993.

[3] R. Krishman, Switched reluctance motor drives, modeling, simulation, analysis, design, and applications, CRC Press, Washington, 2001.

[4] K. Nakamura, Y. Suzuki, H. Goto, and O. Ichinokura, Design of outerrotor type multipolar SR motor for electric vehicle, Proceedings of the Joint European Magnetic Symposia (JEMS'04), vol. 290-291, pp. 787794, April 2005.

[5] J. Dirba, N. Levin, S. Orlova and V. Pugachev, Brushless Synchronous Motors for Appliances and Power Tools, Proceedings of the $6^{\text {th }}$ International Conference on Electrical and Control Technologies (ECT2011), Lithuania, Kaunas, pp. 222-225, May 2011.

[6] V. Pugachev, J. Dirba, L. Kukjane, N. Levin and S. Orlova, "Synchronous Reluctance motor", Patent of the Republic of Latvia LV 14418 B, Jan. 20, 2012 (in Latvian).

[7] M. M. Protodyakonov, R. I. Teder, Method of the experiments rational design, Moscow, Russia: Science, 1973 (in Russian).
[8] A. Janushevskis, J. Auzinsh, Design and analysis of experiments, Riga, Latvia: RTU, 2007 (in Latvian)

[9] QuickField. Finite Element Analysis System. Version 5.7. User's Guide. Denmark: Tera Analysis, 2010.

[10] L. Lavrinovicha, J. Dirba, N. Lavrinovich, Magnetostatic analysis of surface-mounted permanent magnet motor with external rotor for use in electric hand planer. Electric Power Engineering (EPE) Conf., Kouty nad Desnou, Chech Republic, 2013.

[11] N. Bianchi, Electrical Machine Analysis Using Finite Elements, CRC Press, Boca Raton, FL, Taylor \& Francis, 2005.

[12] V. O. Eglays, Aproximation of the tabular data by means of the polynomial functions regression, Problems of the dynamic and strength. Riga, 1981, Nr 36. (in Russian).

[13] O. Onzevs, I. Tihenko, N. Povetkina and J. Dirba. Electronic Motors: Optimization Problems. Latvian Journal of Physics and Technical Science, Nr 3, Riga, Latvia: Prese, 1997, pp. 71-76.

[14] O. Onzevs, J.Dirba, I. Tihenko, Methodology for Visual Estimation of Electronically Commutated Motors. Latvian Journal of Physics and Technical Science, Riga, Latvia, Nr 3., ISSN 0868-8257, 1998, pp. 3237.

[15] J. Dirba, Special mode of synchronous machines, Riga, Latvia: RTU, 1997 (in Latvian).

[16] J. Dirba, L. Lavrinovicha, L. Levin, V. Pugachev, Application of Synchronous Brushless Motors in Electric Hand Tools, Latvia Journal of Physics and Technical Science, Volume 49, Issue 1, pp. 29-34, ISSN 0868-8257, Riga, Latvia, March 2012,

[17] Introduction to optimization with the Excel Solver tool, Microsoft Home page. [Online]. Available: http://office.microsoft.com [Accessed: May. $12,2013]$.

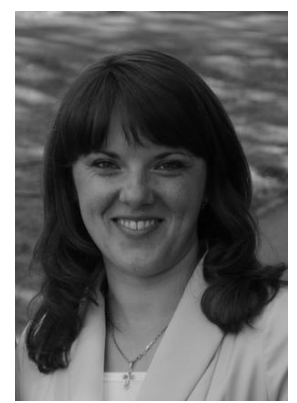

Ludmila Lavrinovicha, doctoral student, Mg.sc.ing. She received Bachelor's degree and Master's degree in electrical engineering from Riga Technical University in 2009 and 2011, respectively. Currently she is a doctoral student at Riga Technical University, Department of Electrical Machines and Apparatus in Faculty of Power and Electrical Engineering.

Fields of scientific interests include magnetic field analysis of synchronous reluctance machines and permanent-magnet electrical machines.

Postal address: Riga Technical University Faculty of Power and Electrical Engineering,

Kronvalda Boulevard 1, Riga LV-1010, Latvia. E-mail: 1.lavrinovicha@inbox.lv

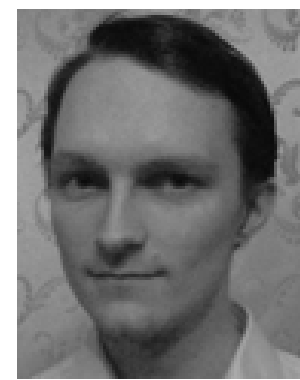

Roman Dobriyan, master student, B.sc.ing. $\mathrm{He}$ received Bachelor's degree in electrical engineering from Riga Technical University in 2012. Currently he is a M.sc. student at Riga Technical University, Department of Electrical Machines and Apparatus in Faculty of Power and Electrical Engineering.

Fields of scientific interests include magnetic field and heat modeling.

Postal address: Riga Technical University Faculty of Power and Electrical Engineering, Kronvalda Boulevard 1, Riga LV-1010, Latvia.

E-mail: exarch1@inbox.lv

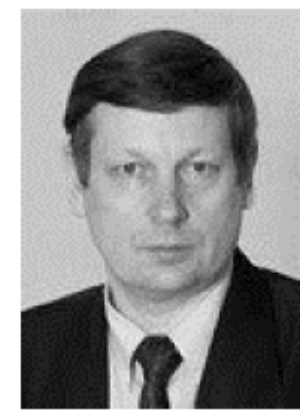

Oskars Onzevs, docent, Dr.sc.ing. He is a leading researcher in Business Technology Institute at Scholl of Business Administration Turiba. He is an author and co-author of more than 50 publications, including 3 patents.

Fields of scientific interests include identification, modeling and optimization of complex systems, application of IT in entrepreneurship, economic and financial models and their applications.

Postal address: School of Business Administration Turiba. Graudu street 68, Riga LV-1058, Latvia.

E-mail: onzevs@turiba.lv 